\title{
Debunking dogma: The arduous task of writing AATS consensus guidelines
}

\author{
Robert James Cerfolio, MD, MBA, FACS, FCCP
}

\author{
From the Division of Cardiothoracic Surgery, University of Alabama at Birmingham, Birmingham, Ala. \\ Disclosures: Intuitive, Neomend, Precision, Bovie, CSATS, CHS, Ethicon, Covidien. \\ Received for publication Jan 27, 2017; accepted for publication Feb 6, 2017; available ahead of print March 7, \\ 2017. \\ Address for reprints: Robert James Cerfolio, MD, MBA, FACS, FCCP, Division of Cardiothoracic Surgery, Uni- \\ versity of Alabama at Birmingham, 703 19th St S, ZRB 739, Birmingham, AL 35294 (E-mail: rcerfolio@ \\ uabmc.edu). \\ J Thorac Cardiovasc Surg 2017;153:e147 \\ $0022-5223 / \$ 36.00$ \\ Copyright (c) 2017 by The American Association for Thoracic Surgery \\ http://dx.doi.org/10.1016/j.jtcvs.2017.02.007
}

The authors have provided consensus guidelines for the management of empyema. ${ }^{1}$ First, we need to express our appreciation to all of those who have sacrificed their time and energy to write guidelines and consensus statements over the years. It is an exceedingly arduous task, especially The American Association of Thoracic Surgery (AATS) guidelines consensus statements. As described in the methods section, the process should not be taken lightly. The entire world's literature is reviewed, the level of evidence is graded, and when data are not sufficient, expert consensus, often a complicated and contentious process, is reached; and this is not even the most impressive part of this article. The most impressive part of it is the high quality and completeness of the review.

The authors have literally covered the gamut of empyema, from antibiotics to the use of fibrinolytics, as well to the use of percutaneous catheters versus video-assisted thoracoscopic surgery (VATS). The authors had the prescience to include an expert in infectious disease and an interventional radiologist on their committee as well. Perhaps my favorite part of this article is the debunking of the myth that we often still hear in our operating rooms today: "epidurals are not safe in patients with empyema." The authors have shown that they are safe, and have also confirmed the well-held theory that fibrinolytics are safe and effective in children, but have a limited role in adults.

It is refreshing to state that there is little to no room for criticism, but because no editorial is complete without some scathing, I will offer a bit. Thoracotomy is rarely if ever needed in the hands of general thoracic surgeons who are well versed in VATS. VATS can almost always, if not always, be successfully used in the empyectomy phase of this operation. The need for a painstaking decortication of the lung in which every nook and cranny is meticulously peeled off is just not required as so many still teach. As long as all the infection is drained, the entire lung is dissected off the diaphragm, pericardium, chest wall, mediastinum, and

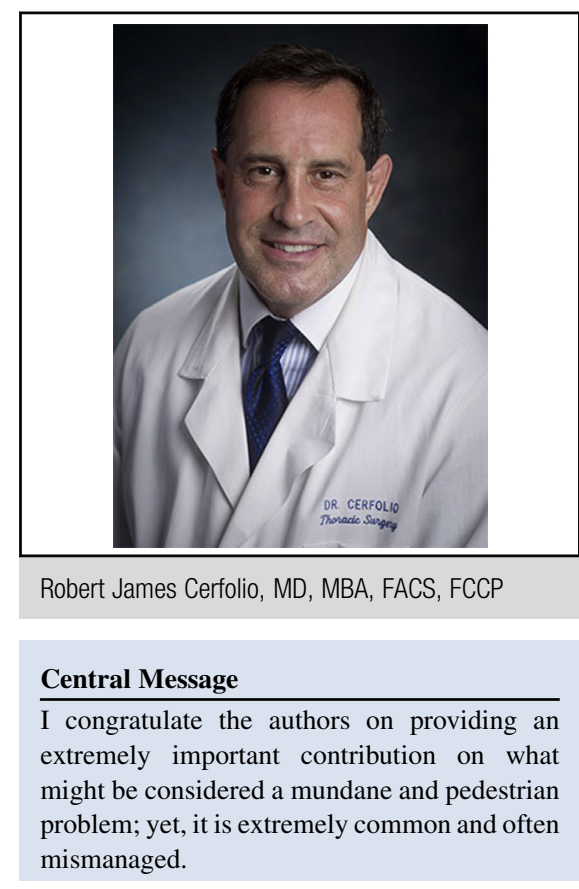

See Article page e129.

between all the fissures, and if a suction catheter when placed in the chest achieves pleural-pleural apposition, a thoracotomy can almost always be avoided. Well-placed chest tubes can be placed on suction and thoracotomy is avoided. Sealants are rarely ever required, even if there are large peripheral air leaks, because little to no lung is resected. Therefore, there is little residual space if the lung is adequately decorticated because it quickly leads to parietal and visceral pleural-pleural apposition. Air leaks, even large ones often seen in the recovery room, resolve overnight.

I congratulate the authors on providing an extremely important and well-written and well-researched contribution on what many might consider a mundane and pedestrian problem; yet, it is extremely common and often mismanaged. It will be frequently cited and will help improve the care of millions of patients in the future.

\section{Reference}

1. Shen RK, Bribriesco A, Crabtree T, Denlinger C, Eby J, Eiken P, et al. The American Association for Thoracic Surgery consensus guidelines for the management of empyema. J Thorac Cardiovasc Surg. 2017;153:e129-46. 